\title{
Open Maloney Repair for Adult Inguinal Hernia, 5 Years Experience in A Remote District
}

\author{
Ahmad S ${ }^{1}$, Ahmed N ${ }^{2}$, Singha $\mathrm{JL}^{4}$, Rayhan $\mathrm{F}^{4}$, Hassan ASMF ${ }^{5}$, Hossain MA ${ }^{6}$, Islam $\mathbf{M}^{7}$
}

Conflict of Interest: None

Received: $14-01-2018$

Accepted: $08-05-2018$

www.banglajol.info/index.php/JSSMC

\section{Key Words:}

Inguinal Hernia. Darning Reapair (Maloney type)

\begin{abstract}
Background: In a remote district city of Bangladesh, inguinal hernias were repaired by Maloney (Darning) method.Efficacy of Darning repair was compared in this study.

Aims and Objectives: The aim of this study was to determine the feasibility of doing Maloney( Darn ) repair for adult inguinal hernias by specialist surgeons at remote districts. Age of the patients in ourstudy were above 20 years.

Study Design: A descriptive retrospective study.

Materials and Methods:In our study we included 2000 patient of inguinal hernia surgery repairs from May 2012 through June 2017. In the patients of the study group we repaired inguinal hernia by Maloney (Darning) technique. Number of patients were 2000 ( male 1990 [99.5\%] female 10 [.5\%] with a mean age of 45.7 years. There were 1002(50.1\%) hernias on the right side, $890(44.5 \%)$ were on the left side and 108(5.4\%) were bilateral. Among the hernias 1419 (70.9\%) were indirect, 575 (28.7\%) were direct and 4 (0.2\%) were of both direct and indirect (Pantoolon type), 2 (0.1\%) were of femoral hernia. All were of primary hernias, recurrent hernias and hernias in patients with apparently weak musculature were repaired by Lychtenistein method with prolein mesh and were not included in this stpudy. 60 (3\%) patients had feature of incarceration and 20 (1\%) patients presented with obstruction. Among the obstructed hernias $8(.4 \%)$ had strangulation and in $2(.1 \%)$ resection and anastomosis were required for gangrenous ileum. In rest of the cases of strangulation circulation returned after incising the constricting ring and hot mob compression. We used IV antibiotic for 24 hours stated with induction of anaesthesia followed by oral for next 6 days. We used Injection Ceftrixone followed by Cefixime and in some patients Flucloxacillin.
\end{abstract}

Statistics Analysis Used: Simple frequencies, proportion and cross tabulation.

Results: Average duration of surgery was 70 minutes. There was no perioperative mortality. 90 (4.5\%) patients developed mild subcutaneous wound infection, haematoma occurred in 160 ( $8 \%)$ patients and seroma found in $300(15 \%)$ patients. All haematoma and seroma subsided gradually. Only 1 patient needed secondary closure for infected wound gap. The average duration of hospitalization was 3 days. All patients in study group are still in contact with me. Three patients (0.15\%) had recurrences. All the recurrent cases reported within 6 months of their operations. Among the three age of 2 patients was above 60 and one patient of age above 70 had Maloney hernia repair for obstructed hernia.

Conclusion:In remote places where prolene mesh is not available or is costly we can repair inguinal hernia by Maloney operation with very simple antibiotics with good results in comparison with other methods.

[J Shaheed Suhrawardy Med Coll 2018; 10(1): 6-10] DOI: http://dx.doi.org/10.3329/jssmc.v10i1.38896
1. Dr. Sami Ahmad, Associate Professor, Department of Surgery, Shaheed Suhrawardy Medical College, Dhaka.

2. Dr. Nadim Ahmed, Senior Consultant, Department of Surgery, Shaheed Suhrawardy Medical College \& Hospital, Dhaka.

3. Dr. Jawher Lal Singha, Associate Professor, Department of Surgery, Shaheed Suhrawardy Medical College, Dhaka.

4. Dr. Ferdoush Rayhan, Medical Officer, Department of Surgery, Shaheed Suhrawardy Medical College \& Hospital, Dhaka

5. Dr. A.S.M. Farhad-Ul-Hassan, Resident Surgery (Casualty), Shaheed Suhrawardy Medical College \& Hospital, Dhaka

6. Dr. Muhammad Anwar Hossain, Junior Consultant (Surgery), Upazila Helath Complex, Karanigonj, Dhaka

7. Dr. Mansurul Islam, Assistant Registrar, Surgery Unit 2, Shaheed Suhrawardy Medical College \& Hospital, Dhaka

Correspondence: Dr. Sami Ahmad, Associate Professor, Department of Surgery, Shaheed Suhrawardy Medical College and Hospital, Dhaka. Mobile: 01711600447. E-mail:dr. sami39@gmail.com.

\section{Introduction:}

Inguinal hernia repair has undergone several modificatons since the description of the Bassini technique. ${ }^{1}$

Malony (Darn) repair for adult inguinal hernia has been used for longtime and is a substitute for tension free mesh repair (Lichtenstein method) and laparoscopic hernia repair in places where prolene mesh is not easily available or patient can not afford to purchase it. Laparoscopic hernia repair needs special set up with expensive instruments and can only be done in big cities with more expenditure. Malony hernia repair is simple to perform with very little facilities and give excellent results with less post operative 
pain and discomfort and acceptable recurrence rate. The underlying factor identified as a cause of recurrence in most of these methods of repair is the fraying or tearing of the fibres of the inguinal ligament due to the significant of tension associated with them. ${ }^{2}$ There are as yet relatively few data on the use of open tension free mesh repair in nonspecialist centres.Our study describes a 5 year experience of darn repair for adult inguinal hernia performed in a remote city hospitals, both private and government with very simple antibiotics and less cost.

It entails approximation of the inguinal ligament to the conjoint tendon with prolene beginning from the pubic tubercle to the internal ring and back to the pubic tubercle without forcibly bring the tissue together with the sutures forming a weave in the posterior wall of the inguinal canal. $^{3,4}$ Patients are still on supervision and only 4 patients came with recurrence till today. Studies evaluating the Darning technique have shown satisfactory outcomes in terms of recurrence and other postoperative complications. Some of these are comparable to Lychtenstein technique of inguinal hernia repair. 5,6

In most parts of South East Asia, studies on inguinal hernia repair using nonprosthetic methods are based on the less acceptable Bassini technique with very few reports on other tissue-based methods such as the Darning technique. $^{7}$

Although, the use of mesh for inguinal hernia repair is now gaining acceptance in our setting, nonprosthetic methods still find relevance in emergency presentation such as obstruction or strangulation, which are not uncommon modes of presentation, ${ }^{8,9}$ and in many hospitals where the experience with mesh repair is limited,

Materials and methods: The study is a retrospective descriptive study. Records of all patients who had inguinal hernia repair from May, 2012 through July 2017 were obtained using the operation registers and case files, only those whose hernias were repaired using the Darning technique were then selected for further review. Statistical analysis was performed using SPSS version 22. Data were expressed as frequencies and proportions with some of quthese presented as tables and charts. Cross- tabulation were done to compare the relationship between recurrence and other variables. Pearson's Chisquare test was done to determine the level of statistical significance while Fisher's test was used in its place when the cases in each cell were $<5$. Statistical significance was set at a $p<0.05$

\section{Results:}

We performed open hernia repair by Darn (Melony) method on 2000 patient of above 20 year old in the District General Hospital and different private clinics of a coastal remote district. Of these 1990 were male and 10 were female. Ages of the patient under our study were above 20 years, ranging from 20 to 110 years with a mean age of 45.7 years. 1012 patients $(50.6 \%)$ were older than 50 years. 108 patients (4\%) had bilateral hernias which were repaired simultaneously except one whose age was above 100 years and general condition did not permit to go for second operation in the same sitting. We repaired it after 3 months. 1991 (99.5\%) operation were done by SAB (sub arachnoid block) and in $9(0.45 \%)$ cases we operated by local anaesthesia infiltration due to their poor general condition and were unfit for SAB block. Of the unilateral cases 1440(72\%) were on right and 560 (28\%) were on left side. Patient with recurrent hernias were not included in the study. $60(3 \%)$ patients presented with features of incarceration and $10(0.5 \%)$ had obstruction. Among the obstructed 2 needed resection and anastomois for their gangrenous gut. We did darn (Melony) hernia repair for all these patients. We used IV antibiotic for 24 hours stated with induction of anaesthesia followed by oral for next 6 days. We used Injection Ceftrixone followed by Cefixime and in some patients Flucloxacillin.

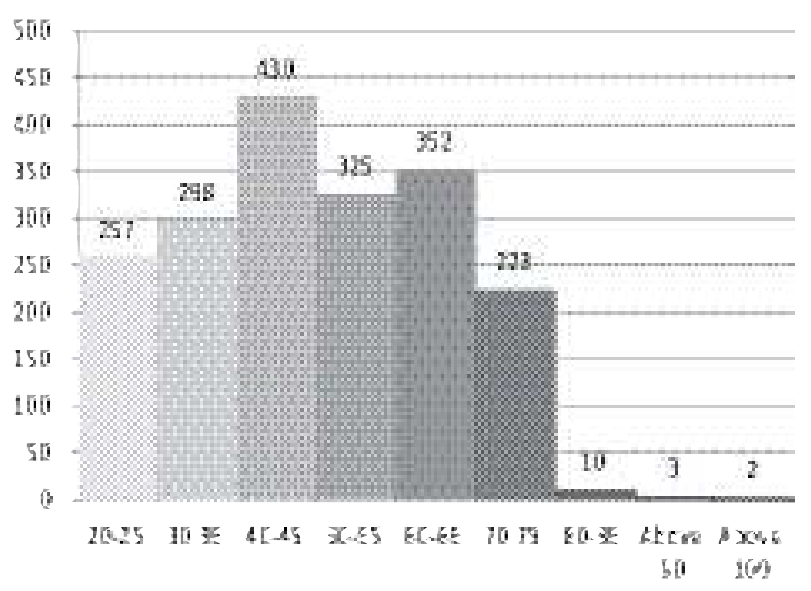

Fig.-1: Number of Patients According to Age

Surgical technique: After ensuring proper anaesthesia an oblique incision was made 2.5 above and medial two third of the line joining the anterior superior iliac spine and pubic tubercle. Inguinal canal is opened through incising external oblique aponeurosis. Structures forming spermatic cord are separated from hernia sac. In case of indirect inguinal hernia sac was amputed $1 \mathrm{~cm}$ distal to the deep ring. Smaller sac was dissected out from the cord structures, in case of larger or complete sac it was transected keeping some portion distally with proper 
hemostasis of the margin. In direct inguinal hernias sacs were usually with broad neck and were everted and invaginated in the peritoneal cavity. For indirect hernias 2-3 prolene stitches were given to narrow the deep ring (Lytle method) by laterally taking the cord which is usually stretched by hernia sac.

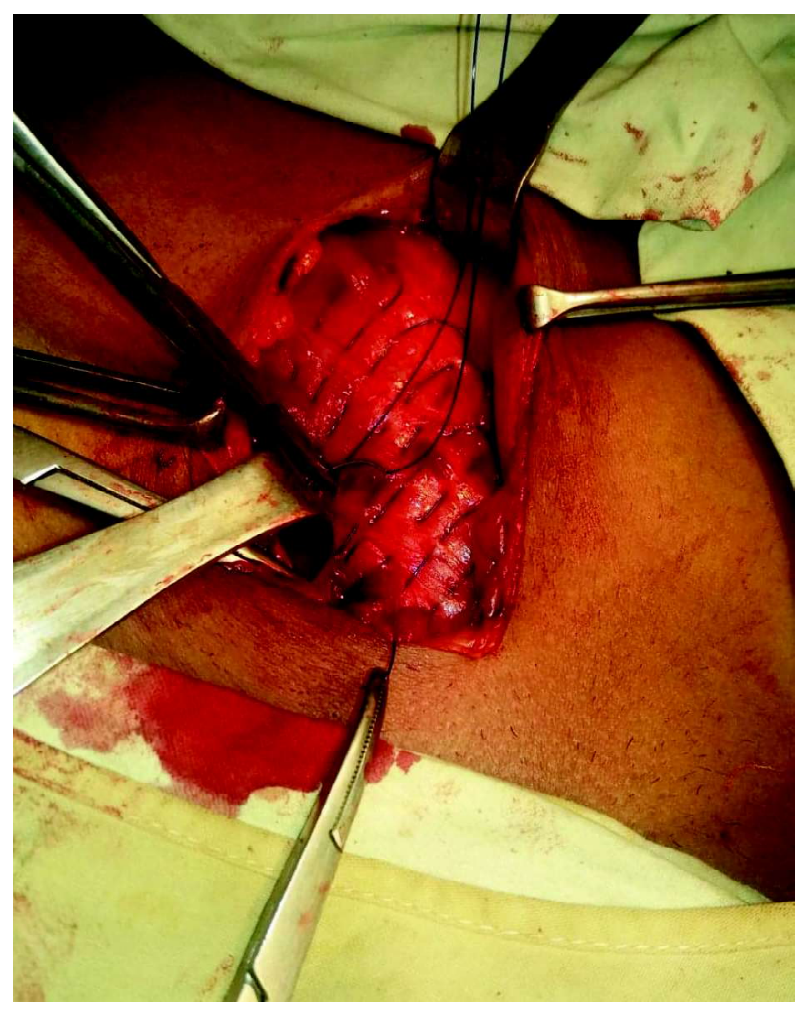

Fig.-2: Darning Method of Inguinal Hernia Repair

\section{Results:}

A total of about 3000 patients had hernia repair during the study period. Of these 2000 patients were selected for these study who had darning type hernia repair for primary ingunial hernia and the patients age was $\geq 20$ yrs. Some of which had feature of obstruction and incarceration. For recurrent hernias and hernia in patient with weak musculature and for large hernia neck we used Lychtenstien procedure.

Further analysis of 2000 patients who had Darning repair showed age range of 20-110 years with a mean age of 45.7 years (Fig- 2). There were 1990 males and 10 females with a male female ratio of 489:1. Majority of the hernias were on the right side 1002 (50.1\%), number of left sided hernias were $890(44.5 \%)$ while 108 cases were bilateral (5.4\%). Most of the hernias were incomplete 1320 (66\%) rest were $680(34 \%)$ complete. In our study only primary hernias were included. 60 patients (3\%) presented with features of incarceration, among wich 12 patients $(.6 \%)$ had intestinal obstruction, relieved by incising the constricting band. 2 patints needed resection and anastomosis of small intestine for gangrene ( Strangulated hernia.) The types of hernia were certained during surgery, revealing 1419 (70.9\%) indirect, 575 (28.7\%) had direct and $4(0.2 \%)$ had both direct and indirect component ( Pantaloon variety). $110(5.5 \%)$ patients were operated un local anaesthesis because of their comorbidity. Mean duration of operation was 70 minutes.

Regarding outcome, surgical site infection was the most common complication recorded occurrig in 122 (6.1) patients. These occurred both in emergency and elective cases with no statistically significant differences. ( $p>0.05)$. All the cases were managed by regular dressing only.About $145(7 \%)$ patients were complaining of chronic groin pain for months. Pain subsided gradually with medication. 4 patients developed recurrence after about mean duration of 15 months. For 5 years rest of the patients are in contact. Preoperatve straining, post operative wound infection, smoking and obesity were not significanty associated with recurrence.

\section{Table-I}

\begin{tabular}{llcc}
\multicolumn{4}{c}{ Post operative complications } \\
SL. No & Complication & Frequency & Percentage \\
\hline 1. & Surgical site infection & 90 & 4.5 \\
2 & Chronic groin pain & 60 & 3 \\
3 & Recurrence & 4 & 0.2 \\
4 & Hematoma & 30 & 1.5 \\
5 & Hydrocoele & 6 & 1.5 \\
\hline & Total & 190 & 12.8 \\
\hline
\end{tabular}

\section{Dicussion:}

The various techniques of inguinal hernia repair can be broadly classified into tissue based and prosthetic method. One major drawback of the tissue based repair has been the amount of tension associated with most of the repair which is an important factor implicated in recurrence. ${ }^{10}$ Though tissue based the darning technique is believed to have an advantage over many other non prosthetic technique being relatively tension free as the posterior wall is repaired without forcefully apposing the tissues. Rather no-1 or 1/0 prolene sutures are passed in a continuous fasion forming a weave in the posterior wall. This method of repair is more common in the United Kingdom and some other English speaking countries where most of the studies on this technique have been 
conducted. ${ }^{11}$ We have used this technique in our patients with inguinal hernias of moderate size in the era of laparoscopic hernia repair except for a few in small cities of our country. Other than darning technique most are done by Bassini method of repair, that should no longer be practiced due to its high recurrence rate ${ }^{12}$. This fact was also observed by Yabooh in his review of inguinal hernia surgery in Africa. ${ }^{7}$ Our study highlights the practice of Inguinal hernia surgery In a district hospital and private clinics of this city using the darning technique.

Our findings with regards to sociodemographic features and hernia characteristics are consistent with what has been documented in previous studiesc ${ }^{13}$ We however observed a reduction in the number of cases presenting with complications, our record of $12.9 \%$ shows a reduction from what has been previously documented in studies in a similar setting where up to quarter of hernias seen presented with complications. ${ }^{9}$ This may be a reflection of improvement in availability and accessibility of health care facilities and also an improvement in public enlightenment. More still needs to be done however as the number a patients presenting with inguino-scrotal hernia $(37 \%)$ still suggests delay in presentation.

In a largely hard working population like ours where occupations with manual labour is common both the development and progression of groin hernias will be common. We hope to engage in effective health communication interventions at community level in conjuction with our community health worker to promote early presentation of abdominal hernias there by reducing the complications in our patients.

There were 4 cases of recurrent hernias in our study using Melony technique (darning) in the mean follow up period of about one year. We have repaired these hernias by prosthetic mesh that is recommended technique in such instances( Lychtenstein Method) ${ }^{14}$

The Darning technique has been acclaimed to have the advantage of a short learning curve particularly when compared with other popular non prosthetic method of repair such ad the Shouldice and Desarda's technique ${ }^{15}$ The procedure can therefore be learned and practice by those who are still performing hernia repair by Bassini method in secondary level public and private health care centres of distric cities.

Chronic groin pain is currently considered an important problem following.

Inguinal hernia repair particularly as it affects the quality of life. It is defined as any visual analog score above zero which lasts for more than 3 months ${ }^{16}$ The $3 \%$ chronic groin pain rate recorded in this study compares well
With the work of Courtnet et al. who also reported a chronic groin pain rate of $3 \%$ in a population- based study of over 5,000 patients who had undergone inguinal hernia repair. ${ }^{17}$

A recurrence rate of $0.2 \%$ in our study is very low in comparison with previous studies that recorded values in the range of $0.6-4 \% 5,18,19$ The low value in our series may be due to that recurrent cases did not report to us or still there is time to report. This is much lower than the $10 \%$ recurrence following Bassini technique in some series and compared to $1 \%$ recurrence rate following Lychtenstein mesh repair. ${ }^{2,6}$ A large follow up period may however reveal a higher recurrence than we noted in this study. All the recurrent cases in our study were unilateral. It is found that patient with bilateral inguinal hernias had a 32 fold risk of developing recurrence when compared to with those unilateral hernias. It remains to be determined however whether this is directly related to the technique or unidentified patient related factors. Patient with undetected bladder outlet obstruction or unidentified connective tissue disorders, for instance may be predisposed to developing multiple hernias and if this is not taken into consideration prior to surgery may also account for recurrence. Thus, patients with bilateral hernias should be evaluated thoroughly for possible underlying factors that may cause recurrence. Such may also be considered for mesh repair as recommended by some Rauthors. ${ }^{20}$

\section{Conclusion:}

Inguinal hernia repair using the Darning technique is a safe and effective method of inguinal hernia repair. We recommend its adoption over the traditional Bassini repair for non-prosthetic repair of inguinal hernias in remote cities in a developing country like us when the supervising surgeon has an sound knowledge of anatomy to make a tension free herniorraphy. A prospective study comparing Darning with the standard Lychtenstein repair in our setting is also recommended. Thus adult inguinal hernias can be repaired by doctors in training in non specialist centres by Darning method with excellent outcome but definitely under supervision.

\section{References:}

1. Bekker J, Keeman JN, Simons MP, Aufenacker TJ. A brief history of the inguinal hernia operation in adults. Ned Tijdschr Geneeskd. 2007; 151:924-31. [ Pub Med]

2. Zsolt B, Csiky M, Recurrence rate in Bassini Operation after 5 years. Magy Seb. 2001;54:307-8, [pub Med]

3. Abrahamson J. Hernias, In: Zinner Mj, editor. Maingot's Abdiminal operations. $10^{\text {th }}$ ed. Connecticut: Appleton and Lange; 1997.pp479-580.

4. Moloney GE, Darning inguinal hernias. Arch Surg.1972; 104:129-30. [Pub Med] 
5. Farooq O, Batool Z, Bashir-ur-Rehman. Prolene Darn: Safe and effective method for primary inguinal hernia repair. $\mathrm{J}$ Coll Physicians Surg Pak.2005:15:358-61. [ PubMed]

6. EU Hernia Trialists Collaboration. Laparoscopic compared with open methods of groin hernia repair: Systemic review of randomized controlled trials. Br J Surg. 2000;87:8607.[PubMed]

7. Ohene-Yeboah M, Abantanga FA, Inguinal hernia disease in Africa: A common but neglected surgical condition. West Afr J Med. 2011;30:77-83. [PubMed]

8. Mbah N. Morbidity and mortality associated with inguinal hernia in Northwestern Nigeria. West AfrJ Med.2007;26:28892. [PubMed]

9. Adesunkanmi AR, Agbakwuru EA, Badmus TA, Obstructed abdominal hernia at the Wesley Guild Hospital, Nigeria. East Afr Med J.2000;77:31-3. [ PubMed]

10. Abrahamson J. Etiology and pathophysiology of primary and recurrent groin hernia formation. Sur Clin North Am.1998;78:953-72.vi. [PubMed]

11. Morgan M, Reynolds A, Swan AV, Beech R, Devlin HB. Are current techniques of inguinal hernia repair optimal? A survey in the United Kingdom. AnnR Coll Surg Engl. 1991;73:3415. [PMC free article] [PubMed]

12. Agbakwuru EA, Olabanji JK, Alatise OI, Katung IA, Onakpoya UU. Single versus two layer suturing for wound closure after inguinal hernia repair. Niger J Clin Pract. 209;12:162-4. [PubMed]
13. Arowolo OA, Agbakwuru EA, Adisa AO, Lawal OO, Ibrahim $\mathrm{MH}$, Afolabi AI. Evaluation of tension-free mesh inguinal hernia repairin Nigeria: A preliminary repore. West Afr J Med. 2011;30:110-3 [PubMed]

14. Simons MP, Aufenacker T,Bay-Nielsen M, Bouillot JL, Campanelli G, Conje J, et al. European Hernia Society guidelines on the treatment of inguinal hernia in adult patients. Hernia. 2009;13:343-403[ PMC free article.] [PubMed]

15. Thapar V, Rao P, Deshpande A, Sanghavi B, Supe AN. Shouldic's herniorrhaphy versus Moloney's darn herniorrha in young patients ( a prospective randomized study) J Postgrad Med.2000;46:9-12 (Pub med)

16, Classification of chronic pain. Description of chronic pain syndromes and definitions of pain termes. Prepaired by the International Association for the studya pain. Sub committee on taxonomy.Pain Suppl. 1986;3:S1-226 [ pub Med]

17. Courtney CA, Duffy K, SerpellMG, O' Dawyer PJ. Outcome of patients with severe chronic pain following repair of groin hernia. Br J Sur. 2002;89:1310-4. [PubMed]

18. El- Bakry AA, Plication darn for the repair of inguinal hernia. A university hoapital experience. Saudi Med J. 2002;23:13479. [PubMed]

19. Koukourou A, Lyon W, Rice J, Wattchow DA. Prospective randomized trial of polypropylene mesh compared with nylon darn in inguinal hernia repair. Br J Sur. 2001; 88:931-4. [PubMed].

20. Amid PK, Shulman AG, Lichtenstein IL, Simultaneous repair of bilateral inguinal hernias under local anaesthesia. Ann Surg. 1996;223:249-52. [PMC free article] [PubMed]. 